\title{
Propuesta de desarrollo de un metodología para la enseñanza-aprendizaje de la lectoescritura con estudiantes sordos mediante la Neurodidáctica
}

\section{Proposal for the development of a methodology for teaching-learning of literacy with deaf students through Neurodidactics}

\author{
CARRANCO, Narcisa de J. ${ }^{1}$ \\ MARTÍNEZ, Lisbet ${ }^{2}$ \\ MÁRQUEZ, Juan L. ${ }^{3}$ \\ REALPE, Leidy V. ${ }^{4}$
}

\section{Resumen}

El presente artículo es resultado de una investigación para fundamentar una concepción didáctica del proceso de enseñanza aprendizaje de la lectoescritura para los estudiantes sordos desde el enfoque de la Neurodidáctica. Se utilizó un enfoque cualitativo, mediante la investigación acción participativa. A partir de la concepción didáctica activa y de los postulados teóricos de la Neurodidáctica, se expone en el trabajo una metodología para la realización de ejercicios para la formación de las habilidades de Caracterización, Categorización, Clasificación y Predicción.

Palabras clave: estrategia didáctica, lectoescritura, neurodidáctica, sordos.

\begin{abstract}
This article is the result of an investigation to support a didactic conception of the teaching-learning process of reading and writing for deaf students from the Neurodidactics approach. A qualitative approach was used, through participatory action research. From an active didactic conception and the theoretical postulates of Neurodidactics, a methodology is exposed in the work to carry out exercises for the formation of Characterization, Categorization, Classification and Prediction skills;

key words: deaf, didactic conception, neurodidactic, reading-writing
\end{abstract}

\section{Introducción}

Enseñar lectoescritura a los estudiantes sordos es una acción que demanda que el docente esté cualificado para saber cuál es la didáctica más acorde a las características de los estudiantes con discapacidad auditiva. Los procesos de enseñanza-aprendizaje, como toda la educación en la actualidad, se favorecen con los avances científicos en el campo de las neurociencias. Se coincide con el criterio de Fonseca y Heredia (2020), sobre la

\footnotetext{
${ }^{1}$ Universidad Técnica de Ambato. Facultad de Ciencias de la Salud. Departamento de vinculación con la sociedad. Ambato, Ecuador. Correo: njcarranco63@gmail.com. ORCID: https://orcid.org/0000-0002-3335-6148

2 Universidad Tecnológica Indoamérica. Facultad de Ciencias Humanas de la Educación y Desarrollo Social. Ambato, Ecuador. Correo:

Imartinez9@indoamerica.edu.ec. ORCID: https://orcid.org/0000-0001-6428-5971

3 Universidad de Pinar del Río. Centro de Estudios de Ciencias de la Educación. Pinar del Río, Cuba. Correo: marqmarrero@upr.edu.cu. ORCID: https://orcid.org/0000-0001-9632-9350

${ }^{4}$ Universidad Técnica "Luis Vargas Torres" de Esmeraldas. Facultad de la Pedagogía. Esmeraldas, Ecuador. Correo: leidy.realpe@utelvt.edu.ec. ORCID: https://orcid.org/0000-0002-2368-3735
} 
importancia de la Neuroeducación, la Neuropedagogía y la Neurodidáctica, pues “...son elementos fundamentales para determinar la eficiente asociación de la didáctica enseñanza - aprendizaje en aras de adaptar programas curriculares que engloben el determinismo educativo reinante y coadyuven a desarrollar didácticas que fortalezcan las competencias cerebrales. (p. 194)

El sistema educativo ecuatoriano pone énfasis en la inclusión educativa. Son diversas las leyes y otros mecanismos legales que promueven el derecho a la educación para todos los ciudadanos. Una de ellas es la Ley de Discapacidades del año 2012, con la que se responsabiliza al Ministerio de Educación de garantizar a niños y jóvenes con discapacidad su integración a la educación regular (Clavijo y Bautista, 2020).

Las instituciones educativas que atiendan niños sordos tienen la responsabilidad de desarrollar acciones pedagógicas acordes a sus necesidades y favorecer su inclusión escolar, universitaria y su inserción laboral. Desconocen que los niños con limitaciones auditivas, pueden aprender a leer y escribir español y facilitar su inclusión al sistema educativo regular, aprobar los niveles de escolaridad e insertarse en el sistema de educación superior.

Cabrera et al. (2004) y Ruiz (2015) consideran que los docentes deben reconocer que los niños sordos tienen limitaciones en su vocabulario, por lo cual, su proceso lector y escritural está afectado y es responsabilidad de los docentes desarrollar estrategias didácticas acorde a sus necesidades, para facilitar el aprendizaje.

La pedagogía actual se beneficia de desarrollos científicos en diferentes campos, como las neurociencias. Su aplicación en el campo educativo, ha originado términos como neuroeducación y neurodidáctica, cuya introducción en los procesos formativos avanza en la solución creativa de los complejos problemas pedagógicos y didácticos actuales. Se coincide con Bueno y Forés (2018), en los aportes que desde estas ciencias se pueden realizar a la formación del ser humano, cuando plantean que "La neuroeducación se está postulando como una herramienta muy potente para mejorar las estrategias educativas y contribuir a dignificar la vida humana, proporcionando datos y evidencias científicas a la pedagogía para que profundice en sus propuestas" (p.23)

Igualmente Muchiut et. al. (2018), valoran positivamente las potencialidades de la vinculación de las neurociencias a la didáctica "en cuanto que es la ciencia que se encarga de estudiar el sistema nervioso central desde su funcionamiento neuronal hasta el comportamiento, cuyo propósito principal es entender como el encéfalo hace conducta (p.208)

Para autores como Calzadilla y Nass (2017), la necesidad de la integración neurociencia-pedagogía para el desempeño docente se debe a que:

En la actualidad, la integración del conocimiento de las neurociencias, en el modo de actuación profesional del docente, responde al hecho de que la Pedagogía, como ciencia de las transformaciones, opera en la forma de pensar, sentir y actuar del sujeto. Estos cambios están estrechamente relacionados con la actividad nerviosa superior, en las condiciones específicas. (p.22)

No obstante, no es un proceso sencillo la utilización por los docentes de las propuestas desde la neurodidáctica, que "se ocupa de estudiar la optimización del proceso de enseñanza y aprendizaje, basado en el desarrollo del cerebro y favorece a su vez el que se aprenda con todo el potencial cerebral que poseemos" (Calatayud, 2018,p.69), ya exige preparación y motivación de los docentes hacia su implementación, pues constituye una nueva alternativa para contribuir a la calidad de los procesos de enseñanza-aprendizaje y sus resultados.

Esta preparación no siempre está presente, lo cual puede provocar tensiones en el docente. Tensión que, como plantean Vesga y Vesga, citados por Díaz y Martínez (2019), proviene:

De la falta de conocimiento de estrategias pedagógicas para tratar adecuadamente a estos discentes, porque el sistema educativo actual intenta introducir inclusivamente a estos niños en 
las aulas ordinarias, pero no suele ofrecer cursos formativos concretos para el profesor que va a tener en su aula a un alumno con $\mathrm{NEAE}^{5}$, sino que más bien organiza cursos de inclusión general (p.147)

Recibe también la neurodidáctica aportes desde otras ciencias, también vinculadas al proceso formativo, aportes destacados por Chávez y Chávez (2020), quienes consideran que:

La neurodidáctica se enriquece tanto de los principales aportes de la psicología y pedagogía, así como de los estudios recientes de un cerebro en vivo que proporcionan las nuevas tecnologías de visualización cerebral, con objetivo de implementar ambientes eficientes e innovadores de aprendizaje. (p.147)

Lazara y Mateos (2018) explican que la neurodidáctica propone varias estrategias para que el maestro pueda estimular el aprendizaje de los estudiantes, las cuales son: facilitar ambientes enriquecidos; tener en cuenta las emociones de los estudiantes; facilitar la interacción entre los estudiantes; activar el cerebro cognitivo; favorecer el aprendizaje colaborativo basado en proyectos y el juego, además activar diferentes áreas sensoriales durante clase y estimular la creatividad.

La Unidad Educativa de Sordos de Imbabura se encuentra ubicada en la parroquia de Tanguarín, en San Antonio de Ibarra, provincia Imbabura, Ecuador. En la institución, las aulas no se encuentran equipadas con herramientas que faciliten el aprendizaje de los estudiantes. La Unidad Educativa cuenta con 49 estudiantes comprendidos desde Primer año General Básico hasta el Bachillerato Unificado y 10 docentes, de ellos 2 de materias como Educación Física y Computación. Se evidenció que la formación profesional de los doocentes era licenciados en Ciencias de la educación, tecnólogos en educación inicial, profesor normalista de educación básica; ninguno de ellos tenía especialidad en Necesidades Educativas Especiales Derivados de la discapacidad, el manejo de señas era el básico y tampoco tenían experiencia en la educación con la población sorda.

A partir de la preocupación y percepción de los docentes de lectoescritura sobre los resultados insuficientes del aprendizaje de esta materia en la unidad educativa, se inicia a inicios del año 2019, un primer acercamiento de alcance exploratorio. La revisión de documentos relacionados con el proceso docente, como planes de clases, programas de las materias e informes de los docentes, entrevistas con los docentes y directivos de la institución, posibilitó determinar la existencia de un conjunto de dificultades relacionadas con la utilización de métodos de enseñanza inadecuados, asi como la falta de preparación necesaria de los docentes para el trabajo con los estudiantes deficientes auditivos, además de que la adaptación curricular no incluye los elementos diferenciales para desarrollar las habilidades en la lectoescritura.

De acuerdo al diagnóstico realizado en el que se analizaron cuatro variables: el concepto que tiene el maestro del niño sordo; de cómo aprende el estudiante sordo; el concepto de cómo enseñarle a un niño con discapacidad auditiva y el concepto del maestro del lenguaje de señas, se pudo comprobar que los maestros de la unidad educativa perciben que los niños sordos no pueden aprender a leer y escribir español, porque la discapacidad auditiva los limita para el aprendizaje. Comentarios como "ellos son lentos por ser sordos" "no pueden aprender" "tienen limitaciones cognitivas", entre otros neuromitos, evidencian que los maestros se centran en la discapacidad de la concepción médica /clínica del estudiante.

En cuanto a cómo se le debe enseñar a los niños sordos, los maestros consideran que este proceso es muy difícil, no saben qué hacer para que los estudiantes aprendan y recurren a las didácticas tradicionalistas centradas en

\footnotetext{
${ }^{5}$ Necesidades Específicas de Apoyo Educativo
} 
la memoria y la repetición; enseñan lo básico sin exigir el cumplimiento de las competencias en la lectoescritura de cada grado.

Por último, en referencia a la conceptualización que tienen los maestros de la lengua de señas, los docentes piensan que este no es un recurso didáctico para la enseñanza de la lectoescritura del español y opinan que el lenguaje de señas sirve para comunicarse entre ellos.

Se observó que no hay una metodología clara; no se evidencian los pasos, las fases o los momentos de la clase y tampoco son claras las estrategias o recursos. Estas regularidades se resumen en el Anexo 1.

Partiendo de esta situación se diseña e inicia un proceso investigativo para fundamentar una concepción didáctica del proceso de enseñanza-aprendizaje de la lectoescritura para los estudiantes sordos, basado en los fundamentos de la Neurodidáctica y potenciar con ella la calidad de la formación de habilidades de los estudiantes de la Unidad Educativa de Sordos de Imbabura. Esta investigación se realizó en el marco del programa de Maestría en Innovación Educativa, de la Pontificia Universidad Católica del Ecuador, del cual tomó parte la autora principal del trabajo como alumna y este trabajo constituyó su tesis en opción a este título académico.

Derivado de este proceso se presenta un conjunto de ejercicios que, basados en las propuestas de la Neurodidáctica, permitan la formación de cuatro habilidades de la lectoescritura: caracterización, categorización, clasificación y predicción. El diseño de estos ejercicios se sustenta en tres componentes esenciales: el fortalecimiento de las dimensiones intelectuales, afectivas y sociales; el desarrollo de didácticas activas; y el lenguaje de señas como recurso didáctico.

\section{Metodología}

Se utilizó un tipo de investigación cualitativa, mediante la investigación acción participativa en el aula. La población del estudio estuvo constituida por ocho maestros, incluida la rectora de la Unidad Educativa, quienes manifestaron su interés por mejorar sus prácticas docentes e indagar el por qué de la dificultad del aprendizaje de la lectoescritura del español en los estudiantes. No se utilizó muestra. Los métodos de investigación utilizados fueron:

- Análisis bibliográfico: Se realizó una revisión bibliográfica sobre el tema, en publicaciones del ámbito educativo, indexadas en bases de datos reconocidas. La selección y análisis del material bibliográfico seleccionado, permitió la sistematización de la teoría sobre la enseñanza-aprendizaje de la lectoescritura para niños sordos y la Neurodidáctica; bases que sustentan teóricamente la propuesta realizada.

- Resúmenes analíticos especializados: Para consolidar y analizar la información de los artículos de revistas indexadas, de libros y de los trabajos de pre y post grado relacionados al tema.

- Diario de campo: Permitió organizar, analizar e interpretar la información recolectada a través de los grupos focales y la observación directa a los docentes, durante la ejecución de la clase de la lectoescritura.

- Grupo focal: Se realizaron 4 encuentros con una duración de 30 a 45 minutos cada 15 días; estuvo conformado por 6 maestros que participaron voluntariamente. Con este instrumento se pudo analizar aspectos sobre las prácticas de enseñanza de los maestros de lectoescritura del español a los niños sordos y elaborar un diagnóstico.

- Observación participante: Este instrumento se utilizó para observar cómo los maestros desarrollaban sus clases de lectoescritura. Se observó el proceso de formación de las habilidades de lectoescritura durante la clase de esta materia. Básicamente la atención de la observación se concentró en cuatro 
aspectos: la metodología utilizada por el docente; los recursos empleados; el desempeño del docente y el desempeño del estudiante.

- Entrevista semiestructurada: Se utilizó para la directora y tres docentes, fue el último instrumento aplicado para identificar las prácticas pedagógicas de los docentes. Ver Anexo 2

\section{Resultados}

Desde la problemática existente y los fundamentos de la Neurodidáctica, se realiza una propuesta de metodología para la enseñanza de la lectoescritura en niños sordos, que sea utilizada por los docentes de la Unidad Educativa de Sordos de Imbabura y tienda a la mejora del proceso de enseñanza-aprendizaje de la lectoescritura. Esta metodología se basa en la realización de ejercicios para el aprendizaje de cuatro habilidades de caracterización; categorización; clasificación y predicción.

\subsection{Ejercicios de caracterización}

Para que el estudiante aprenda es indispensable que el discente organice la información para lo cual debe saber las características del concepto, palabra o tema que va aprender. El proceso de caracterización le permite al cerebro almacenar la información; todo concepto tiene un nombre y tiene unas características propias, esta asociación le permite al cerebro identificar cuando poder usar una palabra, concepto o tema.

La utilización de láminas es importante para apoyarse en la percepción visual del estudiante sordo, en la que establece la relación imagen-palabra. Las palabras deben ser claras y de un tamaño adecuado. Para fortalecer este proceso se pueden utilizar las siguientes láminas:

Figura 1

Relación imagen-palabra

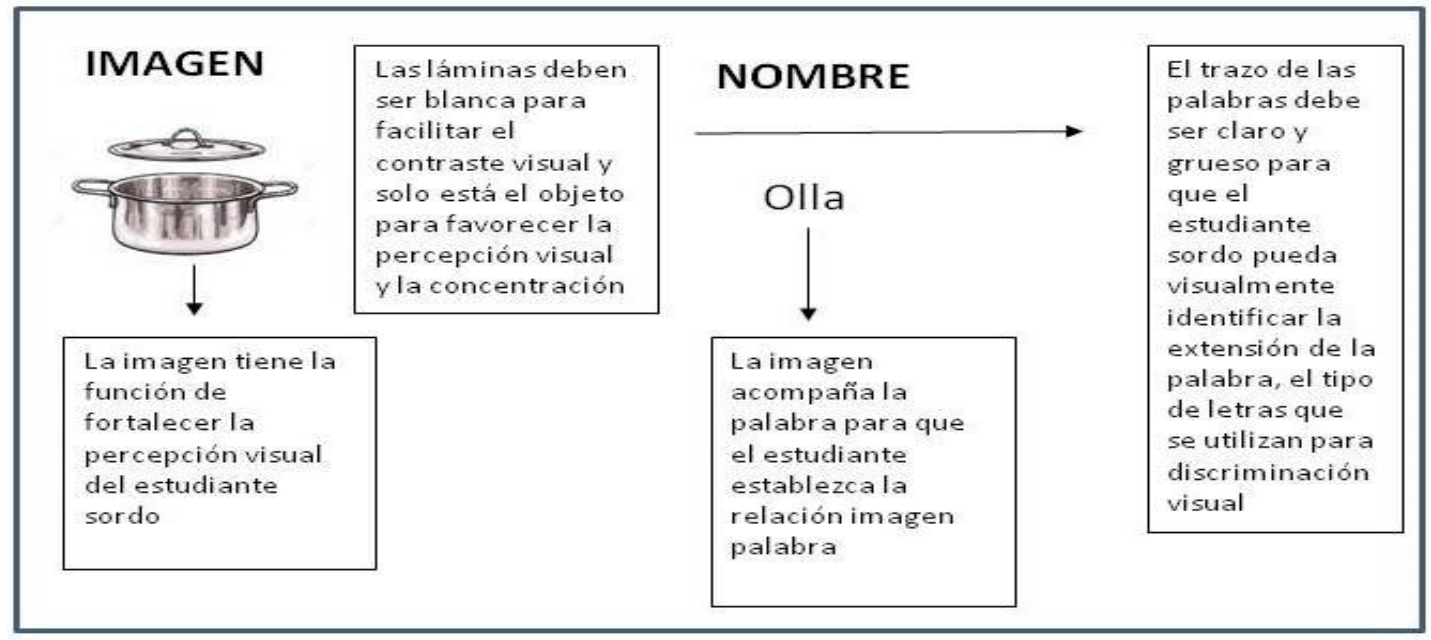

Fuente: Elaborado por los autores

El docente debe repetir varias veces, pero no de la misma forma. Puede inicialmente preguntarles, hacer sociodrama donde utilice el objeto, recurrir a videos, hacer preguntas para qué sirve y sus usos, así se fortalece la memoria a largo plazo y activa diferentes áreas del cerebro y por ende sus conexiones neuronales. 
Figura 2

Proceso de caracterización

imagen-nombre

\begin{tabular}{|c|c|}
\hline IMAGEN & NOMBRE \\
\hline & olla \\
\hline & cuchara \\
\hline & plato hondo \\
\hline & \\
\hline
\end{tabular}

Fuente: Elaborado por los autores

Finalizado el proceso, el discente sordo puede hacer una lectura logográfica de las palabras e identificar las características de las letras (forma y extensión) e identifica qué palabra acompaña cada imagen, sin utilizar señas.

El segundo paso para fortalecer la relación imagen-palabra es presentarle la imagen sin la palabra:

Figura 3

Fortalecer relación

imagen-palabra
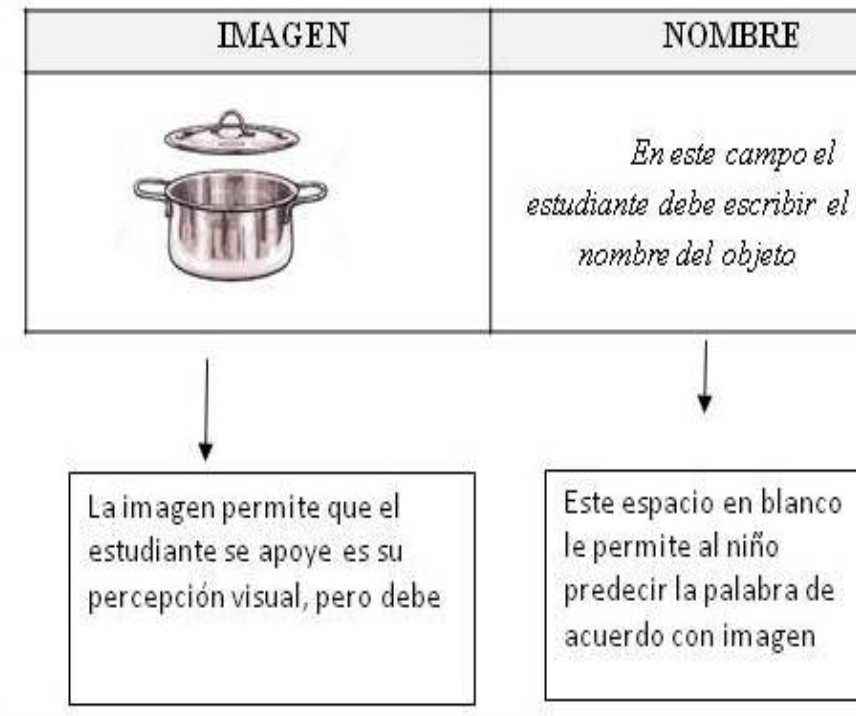

La organización de la tabla le permite al estudiante sordo saber dónde escribir el nombre de la imagen, visualmente puede comprender el ejercicio

Fuente: Elaborado por los autores 
Las fichas se complejizan; se colocan las mismas imágenes, pero ahora el estudiante debe identificar entre varias palabras la relacionada con la imagen, desde la Neurodidáctica este ejercicio favorece los siguientes procesos: atención, concentración y memoria a largo plazo. El ejercicio es individual y los resultados lo puede hacer en pares para fortalecer el aprendizaje y el vínculo socio afectivo entre compañeros.

Figura 4

Identificación de la palabra correcta con imagen

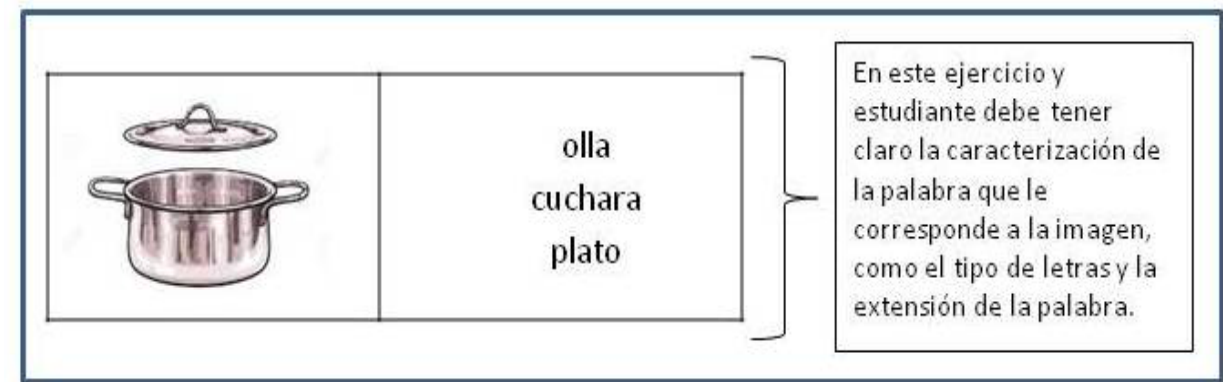

Fuente: Elaborado por los autores

\section{Crucigrama de frutas}

El crucigrama y la sopa de letras son actividades complejas que retan al cerebro para que recupere información sobre cómo se escriben los nombres de las frutas. A continuación, se describe un ejemplo:

Figura 5

Crucigrama

de Frutas

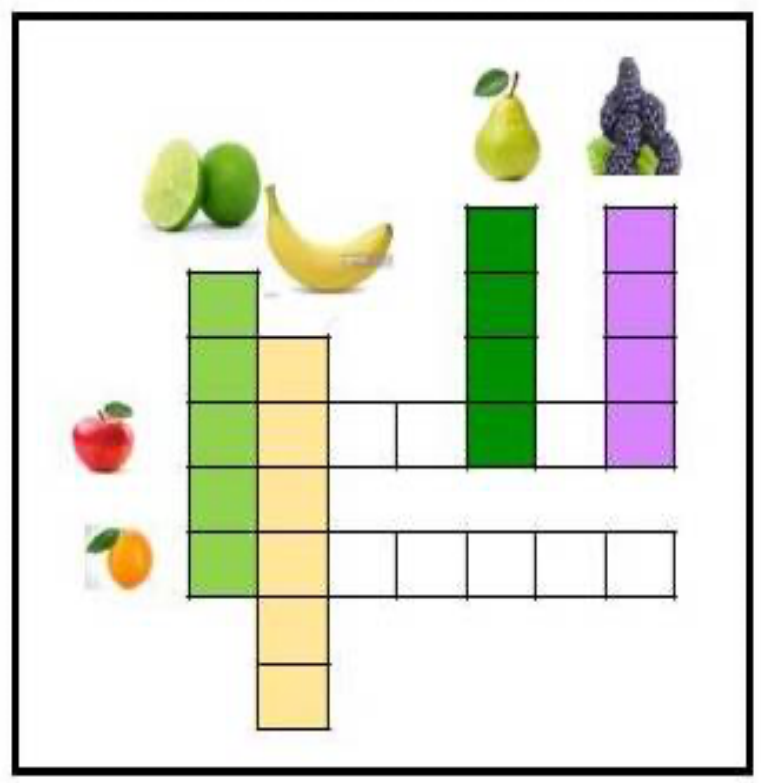

Tomado de: $\underline{\text { https://co.pinterest.com/pin/377035800038227859/?nic v2=1a2bXLiDq }}$

Otra forma de fortalecer la caracterización es por medio de los pares mínimos y la lectura comprensiva. La variante de este ejercicio consiste en mostrar una imagen con cuatro palabras y pregunta ¿Qué es esto?, encerrando en un círculo la respuesta correcta. 


\section{Figura 6}

Lectura de

pares mínimos

\begin{tabular}{|l|l|l|}
\hline ¿Qué es esto? & ¿Qué es esto? \\
\hline Un estuche & Un estuche \\
\hline Un libro & Un libro \\
\hline Una regla & \\
\hline Un cuaderno & & \\
\hline
\end{tabular}

Fuente: Elaborado por los autores

En este ejercicio el estudiante debe tener clara la caracterización de la palabra que le corresponde a la imagen. Pero a la vez se introduce el uso de los artículos "un" y "una".

\section{Ejercicios de categorización}

En este ejercicio para categorizar, se inicia con una caracterización. Se trabajará con láminas u objetos del hogar; puede ser el dormitorio, cocina, comedor, sala, y permitir que el estudiante ordene o vincule la imagen con el concepto, esto es indispensable para que el cerebro fortalezca el aprendizaje, como se muestra en la figura 7:

Figura 7

Tarjetas para caracterizar

los elementos de la alcoba

\begin{tabular}{|c|c|}
\hline IMAGEN & NOMBRF \\
\hline & cama \\
\hline & cobija \\
\hline & \\
\hline & almohada \\
\hline
\end{tabular}

Fuente: Elaborado por los autores

Recuerde: el estudiante ha logrado la caracterización de los elementos de la cocina y la alcoba y ahora debe fortalecer el proceso de categorización. Presente una hoja con el siguiente ejercicio: solicite al niño que con un color rojo encierre lo elementos de la cocina y con color amarillo los elementos de la alcoba, explique que se han formado grupos y que le pongan nombre a cada grupo. 
Figura 8

Categorización de los

objetos de acuerdo a su uso

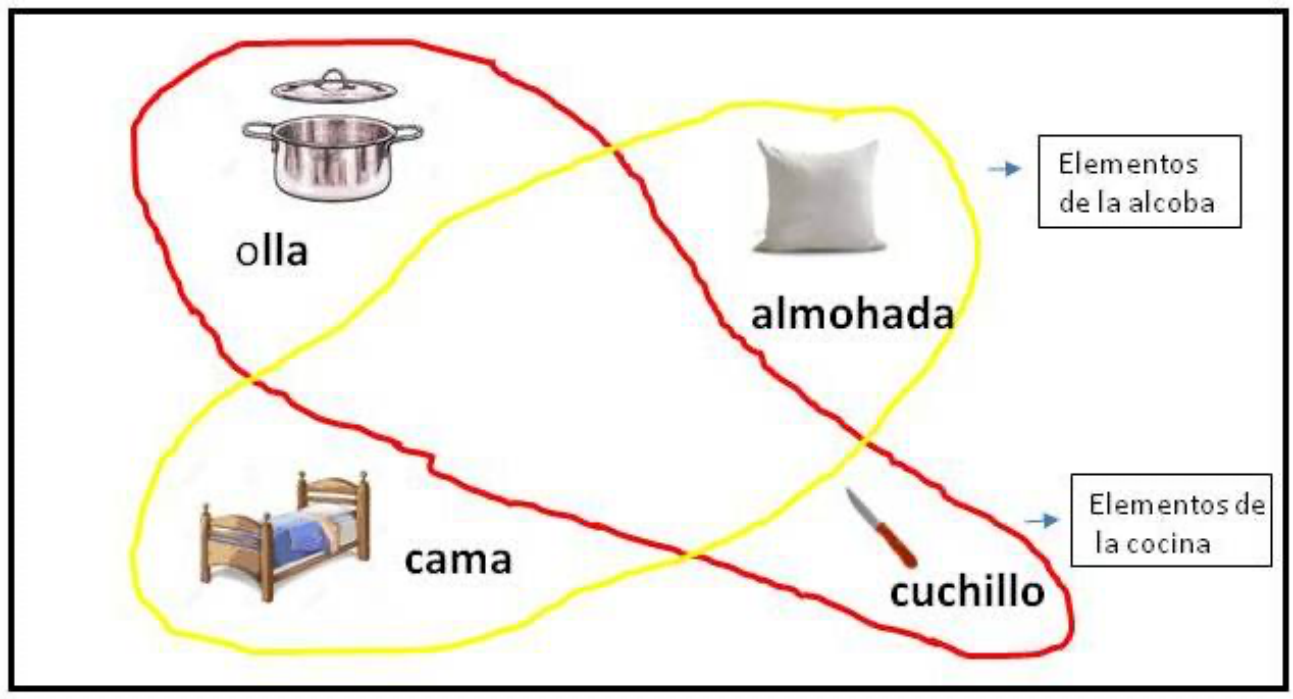

Fuente: Elaborado por los autores

La variante de este ejercicio es eliminar la imagen y solo colocar la palabra para que el niño sordo categorice las palabras entre los objetos de la cocina y objetos de la casa. Esta variante le permite al niño centrarse en las palabras, se complejiza el ejercicio y se reta al cerebro a activar más áreas cerebrales, sí es necesario apoyarse en la lengua de señas.

Otra forma de fortalecer la categorización es por medio de mapas conceptuales

Figura 9

Mapas conceptuales

para categorizar

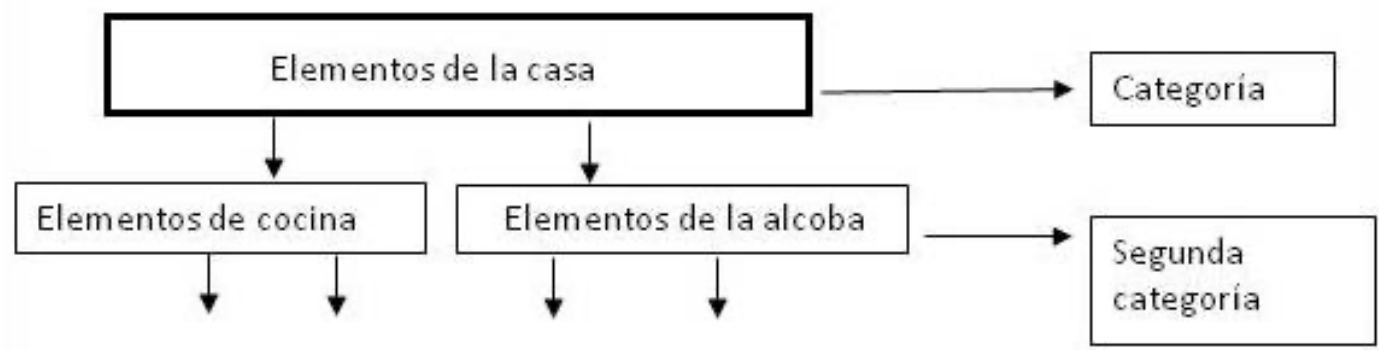

Se colocan las siguientes palabras: cucharón, copa, colchón y cama

Fuente: Elaborado por los autores

El estudiante debe colocar los elementos en la categoría indicada. Gráficamente se le indica al estudiante sordo que siempre van a existir categorías y subcategorías, para organizar las palabras o conceptos. Finalice el proceso con el siguiente ejercicio. Solicite al estudiante que identifique la categoría del conjunto de palabras escritas 


\section{Figura 10}

Identifique la categoría del

conjunto de palabras escritas

\begin{tabular}{|c|c|c|}
\hline $\begin{array}{l}\text { Olla, cucharón, } \\
\text { plato plano, copa }\end{array}$ & La categoria es: & \\
\hline $\begin{array}{l}\text { Rosa, clavel, lirio, } \\
\text { girasol }\end{array}$ & La categoria es: & ... \\
\hline $\begin{array}{l}\text { Cobija, cama, } \\
\text { almohada }\end{array}$ & La categoria es: & ... \\
\hline
\end{tabular}

Fuente: Elaborado por los autores

\section{Ejercicios de clasificación}

La clasificación es un proceso mental que permite al estudiante sordo inferir a qué categoría pertenece un conjunto de elementos. Solicite al niño sordo que identifique, qué elemento no pertenece a la categoría "elementos de la alcoba". Realice por lo menos 15 láminas similares, según modelo.

Figura 11

Categorizar a que conjunto

pertenece los elementos

\begin{tabular}{|c|c|c|c|}
\hline pera & manzana & melón & olla \\
\hline cama & uva & mandarina & plátano \\
\hline
\end{tabular}

Fuente: Elaborado por los autores

Con el siguiente ejercicio enseñaremos a los estudiantes sordos los tiempos de los verbos para lo cual se organiza el siguiente material. 
Figura 12

Complejización para enseñar

tiempos de los verbos

Se hacen las tres columnas para ubicar los verbos según los tiempos y cada columna tiene un color para ayudar visualmente al estudiante sordo y se repite el proceso de categorización

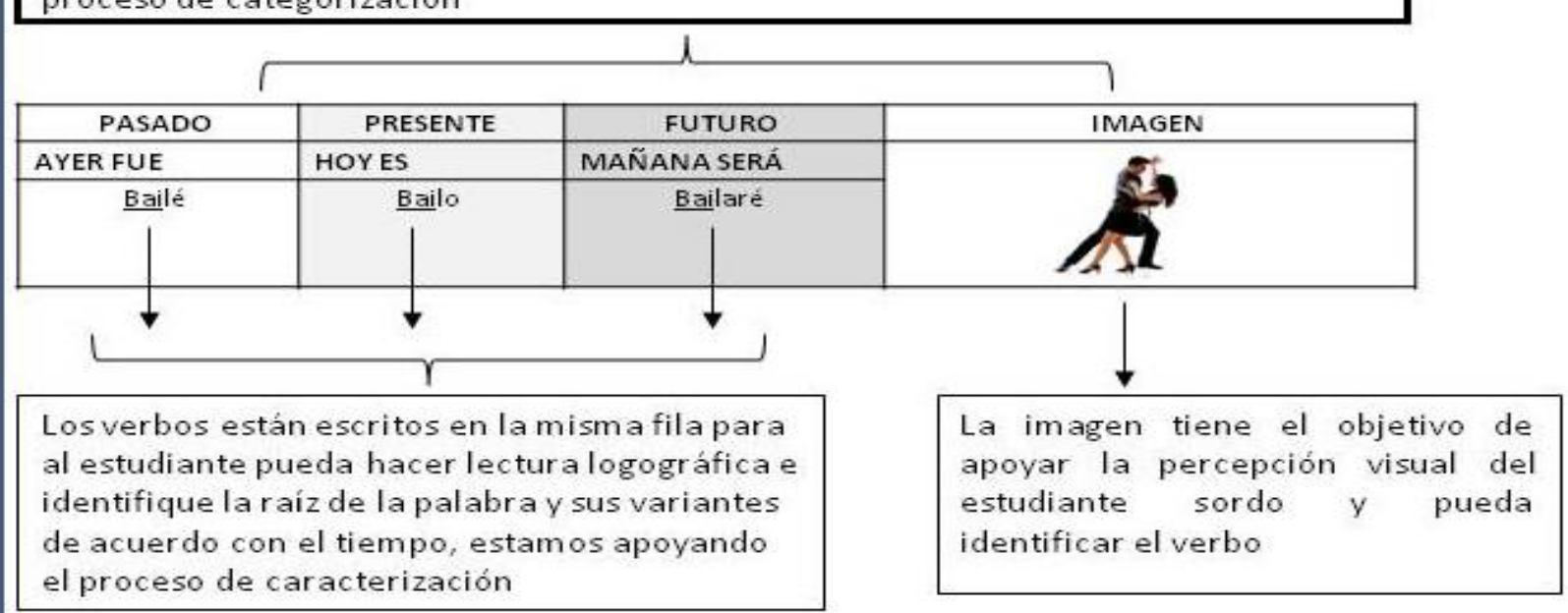

\begin{tabular}{|c|c|c|c|}
\hline $\begin{array}{c}\text { PASADO } \\
\text { AYER FUE }\end{array}$ & $\begin{array}{c}\text { PRESENTE } \\
\text { HOYES }\end{array}$ & $\begin{array}{c}\text { FUTURO } \\
\text { MAÑANA SERÁ }\end{array}$ & IMAGEN \\
\hline He estado & Estar & estare & Leerenacción \\
\hline Lanzó & Lanzar & lanzaré & \\
\hline Lucho & Luchar & lucharé & \\
\hline
\end{tabular}

Fuente: Elaborado por los autores

En el ejercicio propuesto a continuación debemos ubicar al estudiante en el tiempo presente (hoy), trabajar después en el pasado (ayer) y luego el futuro (mañana). Para enseñar conjugaciones, se realizará la introducción de verbos sencillos y poco a poco ir ampliando los mismos; con el objetivo que los estudiantes sordos aprendan a combinar lexema y morfema en cualquier verbo. En algunos verbos que se nos dificulta el aprendizaje, se pueden utilizar señas y dramatización. En verbos irregulares por ser más complejos se debe trabajar en forma individual, para reconocer la concordancia entre el verbo-sujeto. 
Figura 13

Conjugaciones de verbos

\begin{tabular}{|l|l|l|l|}
\hline $\begin{array}{l}\text { PRONOMRRES } \\
\text { PERSONALES }\end{array}$ & PASADO & PRESENTE & \\
\hline Yo & Bailé & bailo & \\
\hline T $\mathbf{u}$ & Bailaste & & bailaré \\
\hline Él, ella, usted & Bailó & & \\
\hline Nosotros/nosotras & Bailamos & & \\
\hline Vosotros/vosotras & Bailasteis & & \\
\hline Ellos, ellas, ustedes & Bailaron & & \\
\hline
\end{tabular}

Fuente: Elaborado por los autores

\section{Ejercicios de predicción}

Predecir implica que el estudiante pueda resolver problemas y pueda indicar la respuesta correcta. En lectoescritura se relaciona con los ejercicios en los cuales el discente debe colocar una palabra, artículo o verbo para que la oración tenga sentido gramatical.

Figura 14

Oración para completar con el verbo

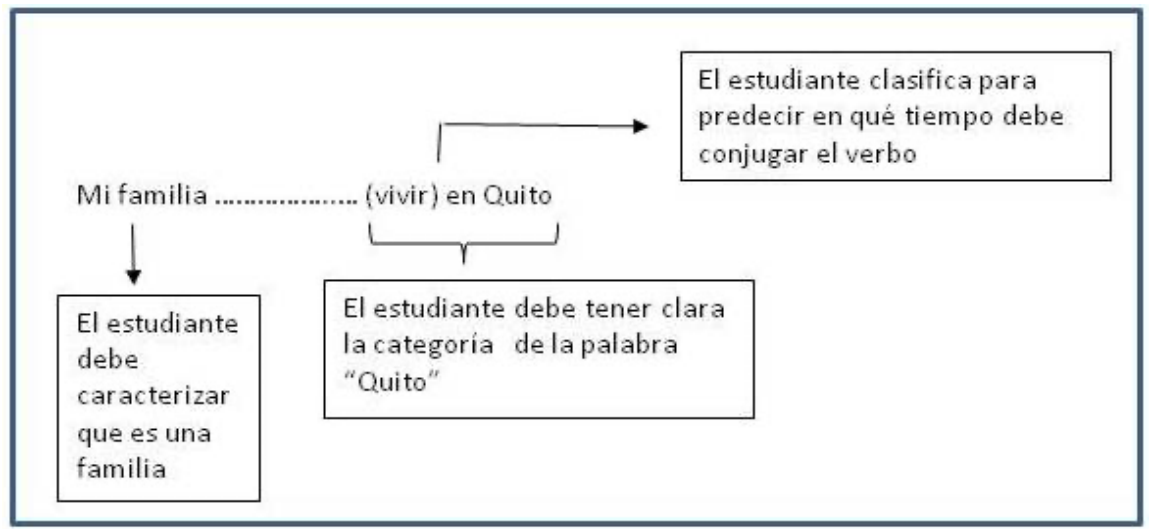

Fuente: Elaborado por los autores

Una variante de este ejercicio es el siguiente: completar la oración

Figura 15

Completar la oración con la palabra correcta.

\begin{tabular}{|l|l|}
\hline & $\begin{array}{l}\text { Papá compra una ............. } \\
\text { bicicleta bicimoto manuela }\end{array}$ \\
\hline & $\begin{array}{l}\text { Ese carro tiene un .................. } \\
\text { valiente velero volante }\end{array}$ \\
\hline
\end{tabular}

Fuente: Elaborado por los autores 
Para fortalecer el proceso de predicción se puede utilizar un cuento, el estudiante debe investigar las imágenes relacionadas, debe identificar palabras nuevas, subrayarlas y buscar su significado en el diccionario.

Figura 16

Iniciación al

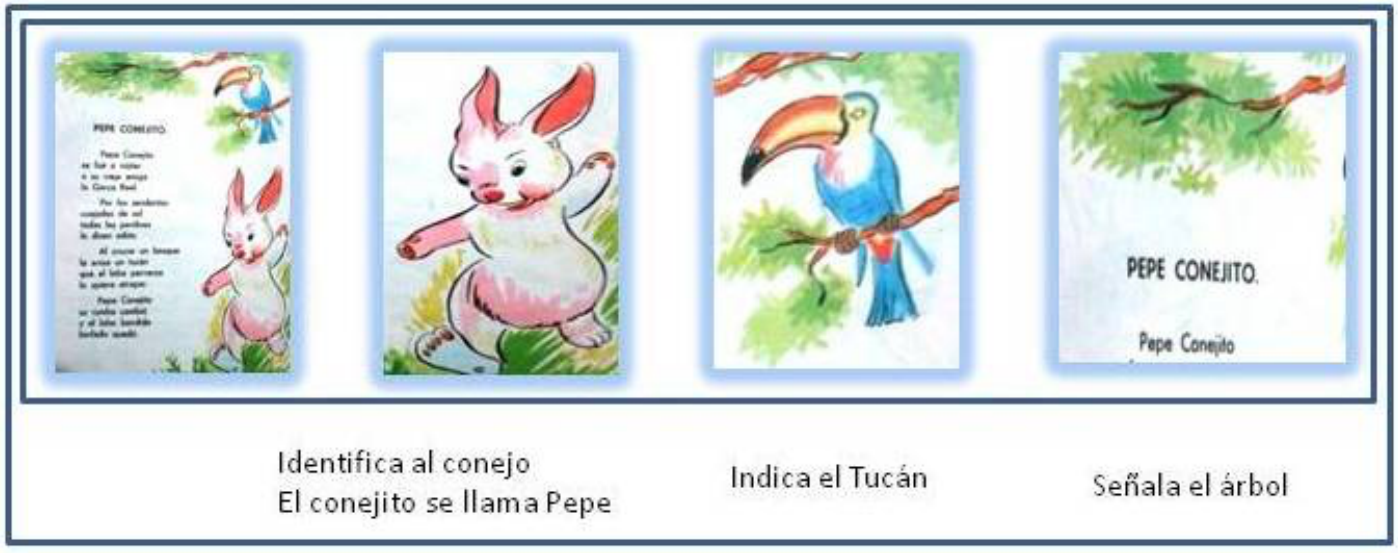

cuento infantil.

Fuente: Tomado de: https://www.pinterest.com.mx/marmelody/ saved/

El estudiante debe leer palabra por palabra y señalando con el dedo índice, con la finalidad que el docente observe dónde se encuentra la lectura del estudiante y pueda visualizar la palabra escrita. Luego se realiza preguntas de selección simple, para que pueda subrayar o encerrar en un círculo.

Figura 17

Preguntas que se realiza de la lectura comprensiva.

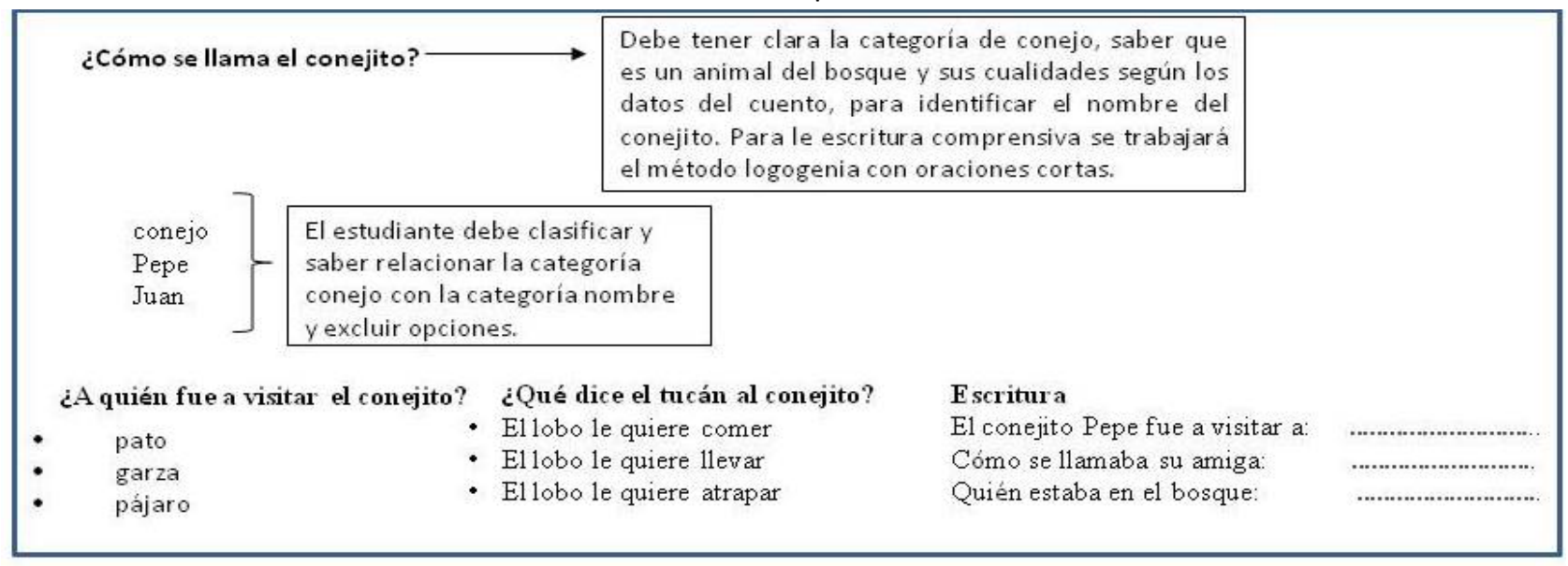

Fuente: Elaborado por los autores.

En la figura 18 se puede observar la síntesis gráfica de la propuesta realizada. 
Figura 18

Aporte metodológico para la enseñanza de la lectoescritura

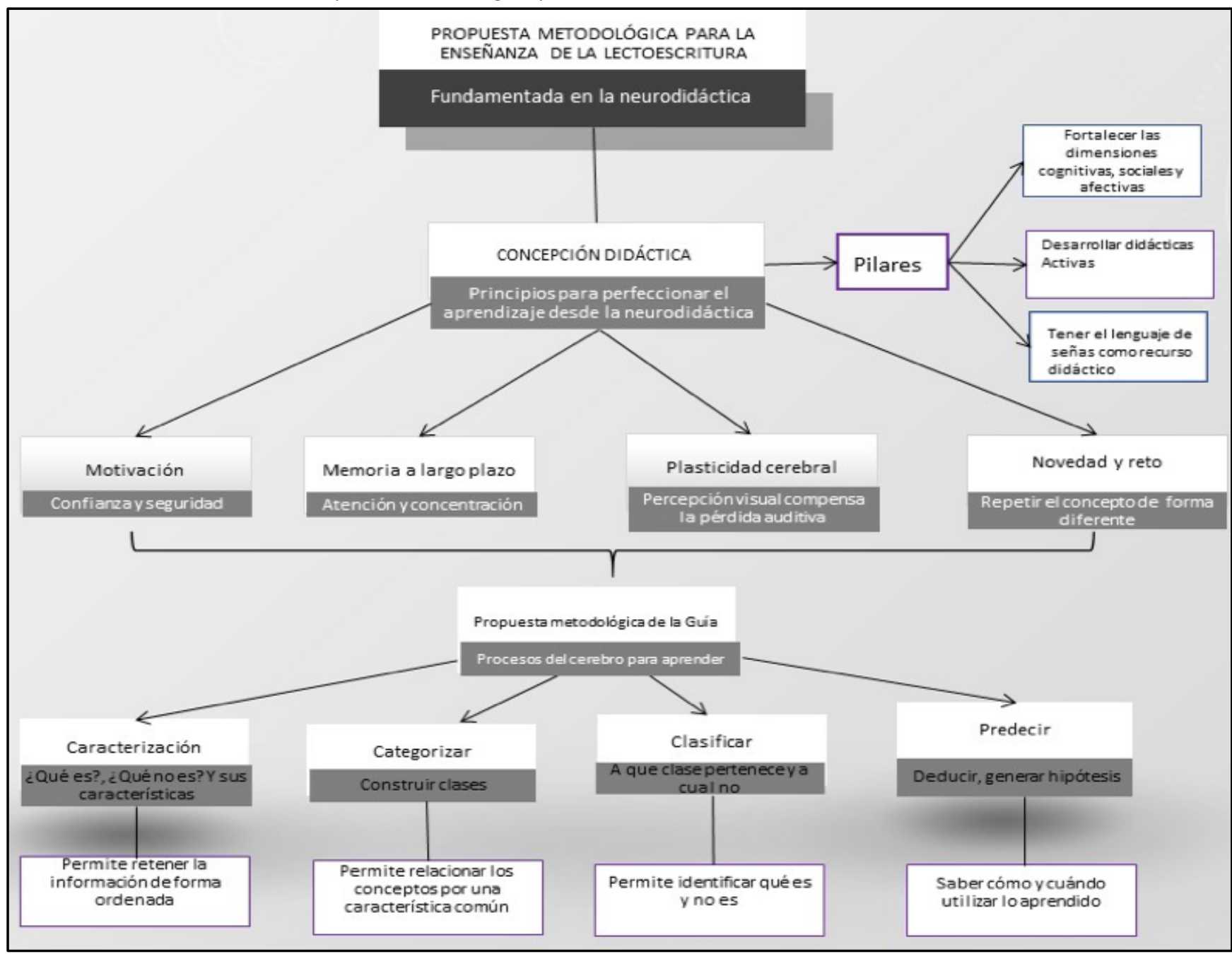

Elaborado por los autores.

\section{Conclusiones}

Los elementos expuestos conforman la propuesta metodológica para fortalecer los procesos de la enseñanzaaprendizaje de la lectoescritura de los estudiantes sordos. Los ejercicios fundamentan desde una estrategia didáctica activa que reconoce que el estudiante sordo tiene las capacidades para aprender a leer y escribir español, pero el maestro debe diseñar didácticas acordes a la realidad del discente, y desde los postulados teóricos de la Neurodidáctica que describe elementos para perfeccionar el aprendizaje, favorecer la motivación del estudiante, fortalecer los procesos de memoria, reconocer la plasticidad cerebral del estudiante sordo y establecer retos y novedad en las actividades que programe el docente.

Esta propuesta se concreta en ejercicios para lograr en los estudiantes las habilidades de caracterizar, categorizar, clasificar y predecir, utilizadas por el cerebro para el aprendizaje. Estos ejercicios, contribuyen a fortalecer la gestión de la enseñanza desarrollada por los docentes de la Unidad Educativa de Sordos de Imbabura, que al aplicarlos en integración sistémica con los componentes curriculares, tienden al perfeccionamiento del proceso de enseñanza-aprendizaje de la lecto escritura para los estudiantes sordos. 
Se dota así a los docentes de lectoescritura de esta institución educativa especializada, de una herramienta metodológica sustentada en los principios de la Neurodidáctica, que contribuye a superar las falencias existentes que limitan los resultados didácticos de la materia, y tributa a la mejora de la calidad de la formación brindada en esta institución.

\section{Referencias bibliográficas}

Bueno, D., Forés, A. (2018). 5 principios de la neuroeducación que la familia debería saber y poner en práctica. Revista Iberoaméricana de Educación. Vol. (78), Núm. 1, septiembre-diciembre, pp. 13-25. https://rieoei.org/RIE/issue/download/282/vol.\%2078\%2C\%20n\%C3\%BAm.\%201

Cabrera, I., Lissi, M. R., Frey, E. (2004). La enseñanza de lectoescritura en la escuela de niños sordos. https://cultura-sorda.org/wp-content/uploads/2016/07/Cabrera-Lissi-etAl-2004.pdf

Calatayud, M. (2018). Hacia una cultura neurodidáctica de la evaluación. La percepción del alumnado universitario. Revista Iberoaméricana de Educación. Vol. (78), Núm. 1, septiembre-diciembre, pp. 67-85. Vol. 78, Núm. 1, septiembre-diciembre. https://rieoei.org/RIE/issue/download/282/vol.\%2078\%2C\%20n\%C3\%BAm.\%201

Calzadilla, O., Nass, L. (2017). La integración de las neurociencias en la formación inicial de docentes. Mendive. Vol. (15) No. 1 (enero-marzo), p.21-40. http://mendive.upr.edu.cu/index.php/MendiveUPR/article/view/969

Clavijo, R., Bautista, M. (2020). La educación inclusiva. Análisis y reflexiones en la educación superior ecuatoriana. Alteridad. Vol. (15), No. 1,113-124. https://doi.org/10.17163/alt.v15n1.2020.09

Chávez, L., Chávez, R. (2020). Neurodidáctica como alternativa innovadora para optimizar el aprendizaje. Revista Varela. Vol. (20). Núm. 56, pp. 145-157. http://revistavarela.uclv.edu.cu/articulos/rv5601.pdf

Díaz, M., Martínez, E. (2019). Análisis de los niveles de estrés en un grupo de maestros con alumnos diagnosticados con trastorno del espectro autista. Revista Española de Discapacidad, 7 (II): 139-154. https://doi.org/10.5569/2340-5104.07.02.08

Fonseca, F., y Heredia, N. L. (2020). La neurociencia como facilitadora en los procesos de formación de los administradores de empresas. Espacios, Vol. (41), Núm. 48, 177-196. https://doi.org/10.48082/espaciosa20v41n48p13

Lazara, Ch. y Mateos, S. (2018). Presentación. Neurodidáctica en el aula: transformado la educación. Revista Iberoamericana de educación. Vol. (78), Núm. 1 9-11. https://doi.org/10.35362/rie7813296

Muchiut, A., Zapata, R., Comba, A., Mari, M., Torres, N., Pellizardi, J., Segovia, A. (2018). Neurodidáctica y autorregulación del aprendizaje, un camino de la teoría a la práctica. Revista Iberoaméricana de Educación. Vol. 78, Núm. 1, septiembre-diciembre, pp.205-219. https://rieoei.org/RIE/issue/download/282/vol.\%2078\%2C\%20n\%C3\%BAm.\%201

Ruiz, E. (2015). El aprendizaje de lecto escritura de niños sordos. Colidoscopio, Revista de contenidos educativos del CEP del Jaen. Num. 2. ISSN: 1989-0281. https://dialnet.unirioja.es/descarga/articulo/3095863.pdf 


\section{Anexos}

\section{Anexo 1}

Problemáticas identificadas por los docentes sobre el proceso de enseñanza-aprendizaje de la lectoescritura en niños sordos de la Unidad Educativa de Sordos de Imbabura.

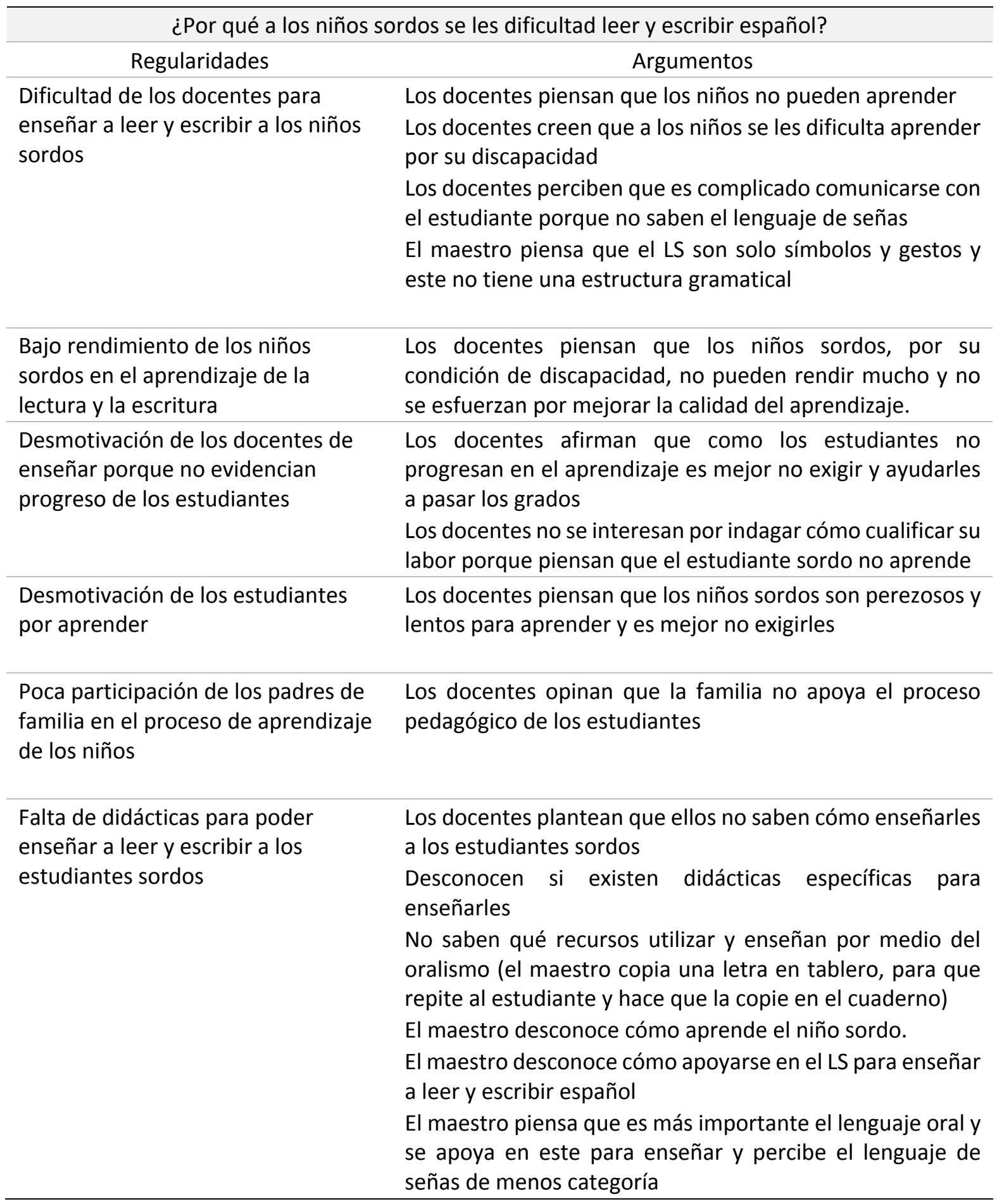




\section{Anexo 2}

Entrevistas semi estructuradas para los docentes y directivos.

\section{Entrevista a docentes}

OBJETIVO ESPECÍFICO: Determinar los métodos, técnicas o herramientas que utilizan para lograr el aprendizaje de los estudiantes

Estimados Docentes: En virtud de recolectar datos para la investigación de la concepción didáctica de los procesos de aprendizaje de la lecto escritura de los estudiantes de la Unidad Educativa de Sordos de Imbabura, se solicita responda las siguientes preguntas, de acuerdo con su experiencia educativa y aplicación de métodos o herramientas que usted utiliza para lograr el aprendizaje de los estudiantes.

Los datos serán utilizados de forma exclusiva con fines investigativos:

PREGUNTAS:

1. ¿Cómo calificaría el nivel de comprensión de la lecto escritura de sus estudiantes?

2. ¿En qué aspectos de la lecto escritura encuentra más dificultad para la práctica?

3. Enseña al estudiante a leer en forma comprensiva

4. De qué forma se da cuenta de que sus estudiantes entendieron la lectura y escritura.

- Por medio de preguntas escritas

- Realización de resúmenes escritos

- Creación de imágenes y señas

- Preguntas usando señas

- Imágenes y señas

5. ¿Cree usted que la lectura silenciosa le ayuda a los estudiantes a entender mejor lo que lee en el texto?

6. ¿Qué tipo de material didáctico utiliza en la lecto escritura?

- Prensa

- Biblioteca de aula

- Libros de biblioteca pública

- Ninguno de las anteriores

7. Describa ¿cuáles son las causas principales de las dificultades de la comprensión lectora y escritura de sus estudiantes.

8. ¿Qué estrategias, métodos, técnicas aplica usted para el aprendizaje de sus estudiantes en la lecto escritura?

9. Usted ha aplicado el método logogenia, para el aprendizaje de la lecto escritura en los sordos.

- Si, la respuesta es Sí, describa qué es para usted la logogenia

10. ¿Usted utiliza la neurodidáctica en el aprendizaje de la lecto escritura, para la enseñanza aprendizaje de los niños sordos?

- Si, la respuesta es Sí, describa qué es neurodidáctica

\section{Entrevista semiestructurada para directivos}

1. Usted opina que los estudiantes de la Unidad Educativa cuentan con los recursos necesarios para enseñar lectoescritura a los estudiantes sordos.

2. Usted, como Directora de la institución, me puede indicar cuáles son los aspectos positivos de los docentes que enseñan lectoescritura del español.

3. Me puede precisar cuáles son las dificultades que tiene los docentes para enseñar lectoescritura a los estudiantes sordos.

- Docentes capacitados

- Cuentan con el apoyo de las Autoridades

- Conocen metodologías apropiadas para los procesos de enseñanza aprendizaje 
4. La institución tiene un programa de capacitación para cualificar a los docentes sobre la enseñanza de la lectoescritura del español.

Esta obra está bajo una Licencia Creative Commons

Attribución-NoCommercial 4.0 International

(cc) EY-NC 